\section{Delta virus as a cleaver}

SIR-Negro et al.' recently reported sequence complementarity between hepatitis delta virus (HDV) RNA and human 7S RNA, the essential RNA component of the signal recognition particle (SRP), and suggested that HDV RNA exerts its pathogenic effect by base-pairing with the $7 \mathrm{~S}$ RNA. We would like to suggest that instead of simply pairing to 7S RNA, HDV RNA might subsequently inactivate it by catalytic cleavage.

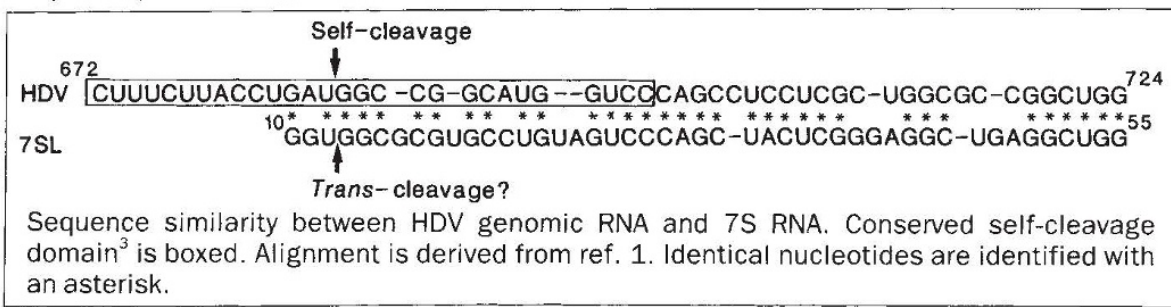

In infected cells, both genomic and anti-genomic HDV RNA can be detected. In vitro, multimeric copies of both genomic and anti-genomic HDV can self-cleave ${ }^{2-4}$. A minimal contiguous selfcleavage domain (approximately 100-130 nucleotides) has been described for both strands and is apparently unrelated to the well characterized 'hammerhead' selfcleavage domains found in a variety of small RNAs ${ }^{5}$. The HDV catalytic domains of genomic and anti-genomic RNAs contain similar, approximately 25 -nucleotide, sequences".

Interestingly, a subset of the genomic self-cleavage domain, including the cleavage site, is found in 7S RNA (nucleotides $10-31$ in the figure). This suggests that the $7 \mathrm{~S}$ sequence could interact with the self-cleaving catalytic centre in HDV, resulting in cleavage of $7 \mathrm{~S}$ at residue 12 . Because the self-cleavage domains of the genome and anti-genome are similar in sequence, the same interaction is possible for the anti-genomic RNA. We suggest that both strands of HDV RNA, not just the anti-genomic strand, may play essential roles in the pathogenesis of HDV.

The capacity of catalytic RNAs to operate on substrates in trans has been recognized for several years ${ }^{5.7}$. In group I intronderived RNA enzymes (ribozymes), substrate selection occurs through basepairing between the substrate and a sequence in the ribozyme's catalytic core? We suggest a similar mechanism for HDV substrate recognition. The processed HDV genome, although no longer a substrate for self-cleavage, may retain

\footnotetext{
1. Negro, F., Gerin, J. L., Purcell, R. H. \& Miller, R. H. Nature 341, 111 (1989)

2. Sharmeen, L.M., Kuo, M. Y.-P., Dinter -Gottlieb, G. \& Taylor, J. J. Virol. 62, 2674-2679(1988).

3. Kuo. M.Y.-P., Sharmeen, L., Dinter-Gottlieb, G. \& Taylor, J. J. Virol. 62, 4439-4444 (1988)

4. Wu, H.N. et al. Proc natn. Acad. Sci. U.S.A. 86 1831-1835 (1989).

5. Uhlenbeck, O.C. Nature 328, 596-600 (1987).

6. Gowans, E.J. et al. Virology 167, 274-278 (1988),

7. Zaug. A.J., Been, M. D. \& Cech, T. R. Nature 324, 429-433 (1986).
}

catalytic activity on substrates such as $7 \mathrm{~S}$, supplied in trans.

In this model, HDV cleavage would remove the 5'-terminal 12 nucleotides of $7 \mathrm{~S}$ RNA, within the region of SRP required for translational arrest of secretory and membrane-associated proteins. Because HDV replicates in the nucleus ${ }^{1.6}$, cleavage of $7 \mathrm{~S}$ could occur before assembly of the mature ribonucleoprotein. RNA-catalysed cleavage of $7 \mathrm{~S}$ RNA

would prevent translational arrest of secretory and membrane proteins, causing ectopic expression of these proteins in the cytosol. If this is correct, HDV may be thought as an infectious ribozyme.

Sequence similarity between HDV and 7S RNA indicates additional intriguing possibilities. By binding components of the SRP, HDV may deplete the cell of SRP proteins or even facilitate its own export from cells by exploiting the host protein-transport machinery. Finally, as a large portion of the conserved HDV self-cleavage domain is present in the 7S sequence, 7S RNA may itself possess catalytic activity.

BENJAMIN YOUNG* BRIAN HICKE*†

* Department of Molecular, Cellular and Developmental Biology. University of Colorado at Boulder, Boulder, Colorado 80309-0347, USA, and

†Medical Scientist Training Program

University of Colorado Health

Sciences Center,

Denver, Colorado 80262, USA

\section{Bone-conducted sound}

SIR-Kermack ${ }^{1}$, in his recent News and Views article about hearing in early mammals, refers to the lightness of the middleear ossicles as a feature contributing to the ability of modern mammals to detect much higher frequencies than birds or reptiles. He does not, however, mention what I believe to be the main advantage conferred by the mammalian system of ossicles - the attenuation of boneconducted sound. Studies by Ernst Bárány providing strong evidence for this function ${ }^{2}$ were published in full in 1938 but have not received the attention they deserve: this function is not mentioned in any account of auditory physiology (admittedly only in English) that I have read.

Bárány proposed that in a bird or reptile with only a single ossicle (the columella auris, connecting the eardrum directly to the oval window), bone-conducted sound is generated mainly as follows. When the skull undergoes vibration with a component along the columella, the inertia of the columella causes it to move relative to the skull, thus causing movements of the inner-ear fluids in the same way as if it were being displaced by sound vibrations impinging on the eardrum. In the mammalian ossicle system, however, the head of the malleus acts as a counterweight, bringing the centre of mass of the whole ossicular chain very close to the axis about which the incus and malleus are pivoted relative to the skull. Thus, when the skull vibrates, the whole ossicular chain moves with it - the footplate of the stapes does not move relative to the oval window, and the inner ear fluids are not displaced.

Bárány demonstrated this mechanism in humans by elegant measurements of bone-conducted sound, using a null method in which the auditory sensation was brought to a minimum by adjusting the amplitude and phase of airborne sound applied simultaneously. He showed that the enhancement of bone conduction when mass is applied to the eardrum (a phenomenon discovered by his father Robert Bárány ${ }^{3}$ ) is due to the centre of mass of the ossicles being shifted off the axis of the pivot.

Bárány makes the point that, in quiet surroundings, bone-conducted sound generated by breathing, chewing, creaking in joints and so on, forms the main background noise above which external sounds have to be detected, so that the range at which, for example, a prey animal can detect a predator will be increased by reducing this background. On the other hand, the function customarily attributed to the ossicles (that is, improving the match between airborne sound and the inner-ear fluids by the $3: 2$ reduction in the lever action of malleus and incus) would be equally well achieved by a 33 per cent reduction in area of the footplate of stapes (or columella), and would therefore provide no selective advantage in evolving the complex system of ossicles.

It would be interesting to know whether the arrangement of the quadrate and articular bones in Morganucodon and in other early mammals was such as to balance out, even if imperfectly, the generation of bone-conducted sound.

The Master's Lodge,

ANDREW HUXLEY

Trinity College.

Cambridge CB2 1TQ, UK

1. Kermack, K. Nature 341, 568-569 (1989)

. Bárány, E. Acta oto-lar. Suppl. 26 (1938)

3. Bárány, R. Mschr. Ohrenheilk. Lar-Rhinol. 44, 549(1910). 